\title{
Historic production evaluation in Biochemistry Education area during the SBBq annual meetings between 1993 and 2016
}

\author{
Pereira, A. V. ${ }^{1}$, Gonçalves, N. N. ${ }^{12}$, Hornink, G. G. ${ }^{3}$ \\ ${ }^{1}$ Instituto de Química, Unifal-MG, MG, Brazil; ${ }^{2}$ Graduanda de Biomedicina, Unifal- \\ MG, MG, Brazil; ${ }^{3}$ Mestrando em Química, Unifal-MG, MG, Brazil
}

INTRODUCTION: The annual meetings of the Brazilian Society Biochemistry and Molecular Biology (SBBq), with the inclusion of the area of education in Biochemistry in 1993, present themselves as important spaces for the presentation and discussion of the work in the area of Biochemistry and Molecular Biology teaching. OBJECTIVES: Systematize and evaluate the historical development of abstracts in the Education in Biochemistry area, in the SBBq annual meeting, indicating quantitative and qualitative data. MATERIAL AND METHODS: A total of 408 abstracts were evaluated, from the panels presented in the area of Education in Biochemistry, from 1993 to 2016. The quantitative evaluation was done by surveying the thematic content, institutions, regions, methods and qualitative analysis based on content analysis (Bardin) of the works of the two most frequently approached themes. RESULTS AND DISCUSSION: The works of the southeast region $(65,4 \%$ of papers presented) were highlighted, with $32 \%$ of the works with qualitative methodology, $10 \%$ quantitative and $33 \%$ quali-quantitative. The most studied topics were Biochemistry teaching (107 papers) and metabolism (94 papers). In the contents analysis of the two most frequently addressed themes, the constructivist and socio-interacionist foundations as the most used teaching-learning processes, as well as the use of software as the most used didactic strategy in both themes. The most used didactic resources were texts / informative in the subject of Teaching of Biochemistry (33\%) and games (21\%) in the subject of Metabolism. CONCLUSIONS: The results evidenced the major focus of the work addressing undergraduate courses, with a qualitative or quantitative method, focusing mainly on Biochemistry teaching, as well as on metabolism, with an expressive amount of activities using educational software, followed by practical classes. There has been a change in the prevailing fundamentals of the teaching-learning process with the emergence in the last years of works with foundations in significant learning.

KEYWORDS: Biochemistry education; SBBq annual meeting; historic production 